\title{
Concomitant Medication Use Indication
}

National Cancer Institute

\section{Source}

National Cancer Institute. Concomitant Medication Use Indication. NCI Thesaurus. Code C83085.

A signal which serves to indicate or point out the specific use cases for a particular concomitant medication. 